\title{
HEGEL E W. BENJAMIN: UM BREVE ESTUDO SOBRE A CRISE DA ARTE NA MODERNIDADE
}

Michele Gomes Alves

\section{RESUMO}

Pergunto se a exposição, na obra Estética, dos argumentos de Wilhelm Friedrich Hegel em defesa da obra-de-arte - por se achar essa, apesar de ser um produto do espírito, na iminência de seu fim - em paralelo com as ideias de Walter Benjamin no ensaio "A obra de arte na era de sua reprodutibilidade técnica" aponta para fenômenos diversificados ou não, da crise da arte na época moderna.

Palavras-chave: Hegel. Benjamin. Arte Moderna. Produto do Espírito. Reprodutibilidade Técnica.

\section{HEGEL AND W. BENJAMIN: A BRIEF STUDY ABOUT THE CRISIS OF MODERN ART}

\begin{abstract}
I wonder if the exhibition, in the book Aesthetics, of arguments by Wilhelm Friedrich Hegel in defense of the work of art - for it to be, despite being a product of the spirit, on the verge of its end - in parallel with the ideas of Walter Benjamin in his essay "the Work of art in the Age of Mechanical Reproduction" indicates diversified phenomena or not, of the crisis of art in the modern age.
\end{abstract}

Keywords: Hegel. Benjamin. Modern Art. Product of the Spirit. Technical reproducibility.

\section{INTRODUÇÃO}

O contexto marcado pela técnica moderna afeta os saberes como um todo, inclusive, o da estética, fato que comprova uma crise no sentido da arte antes compreendida como algo capaz de tocar a espiritualidade humana, num sentido positivo do termo. Esta é a temática sobre a qual iremos nos debruçar neste trabalho, partindo de dois autores de relevante importância no cenário filosófico, quais sejam, Hegel e Benjamin. O primeiro ocupando-se da arte como produto do espírito e o segundo traçando uma crítica à perda da aura, compreendida como o encantamento ou a magia imanente a obra de arte autêntica, que segundo Benjamin se perde a partir da desvalorização do conhecimento da tradição e da expansão da 
ciência e de uma sociedade marcada pela regularização das forças mágicas e religiosas que se manifestam no rito e o crescimento da racionalização instrumental.

\section{A ARTE EM HEGEL}

Para Hegel, a Estética ocupa-se do belo artístico, por ser esta beleza proveniente do espírito. Assim se dá a superioridade da beleza artística com relação à beleza natural e a manifestação dessa superioridade ocorre por meio da arte. $\mathrm{Na}$ defesa desse ponto de vista o filósofo explicita que, sendo o belo artístico produto do espírito é evidente a sua posição elevada com relação à natureza. Segundo Hegel, não existe beleza na natureza, pois é o homem que engendra a característica de belo na natureza, ou nas palavras do autor, "o belo natural será assim, um reflexo do espírito"1 (das Naturschöne [erscheint] nur als ein Reflex des dem Geist angehörigen Schönen) $)^{2}$ E esta arte deve assumir-se verdadeiramente e não submeter-se à simples imitação.

Não sendo produto da experiência sensível (sinnlich), a arte tem representações e intuições internas para sua realização, ou seja, existe no espírito como manifestação da atividade espiritual. Ao analisar o ponto de partida da Estética, Hegel defende que a ciência natural tem seu objeto determinado, enquanto que as ciências relacionadas ao produto do espírito necessitam de uma introdução, visto necessitarem de uma análise e ampliação das concepções, até então defendidas acerca do belo, para dessa forma estabelecer uma definição segura desse assunto.

Através da demonstração e da justificação é possível se perceber o caráter de necessidade presente na Filosofia da arte, sendo o conceito de arte advindo do sistema da filosofia. No entanto, Hegel na Estética não pretende examinar este sistema e sua relação com a arte, por isso permanece distante do conceito científico de arte.

$\mathrm{Na}$ filosofia, as representações se dão a partir de elaborações interiores e aceitam apenas aquilo que tenha um caráter de necessidade, estas necessidades

\footnotetext{
1 HEGEL, Estética, 1993, p. 3.

2 HEGEL, Vorlesungen über die Ästhetik I, Frankfurt am Main: Suhrkamp Verlag, 1986, Seite 15. 
precisam ser provadas e demonstradas. Ora, tudo na filosofia mostra-se com o valor de resultado constatado racionalmente.

O filósofo parte da verificação das representações da existência de obras de arte perante nós, para tentar justificar a representação geral e mostrar a conexão desta com o conteúdo. A arte é uma das formas de exposição do espírito e esta exposição singular é uma espécie de resultado proveniente do espírito.

Partindo destas observações, Hegel passa a confrontar as ideias que se contrapõem a ideia de uma filosofia da arte. Uma dessas objeções é a infinidade do domínio do belo e a outra se refere ao belo como produto da imaginação, do sentimento e, portanto, não pode ser tido como ciência. Nesta ultima objeção, Hegel faz referência aos argumentos kantianos expostos na Crítica do juízo e ainda reconhece Baumgarten como primeiro a denominar a Estética como ciência das sensações, dando assim, reconhecimento às concepções de tal filósofo.

A arte é o primeiro momento de busca da verdade por meio racional, por isso, é tido como extensão do humano e é no homem que se encontra a síntese entre a natureza e o absoluto. A arte já na modernidade perdeu aquela plenitude intrínseca à arte da antiguidade já que é tida apenas como objeto de representação. O belo artístico por si e em si deve ser manifestação do espírito absoluto e não apenas expressão de generalizações que permanecem estranhas aos sentimentos e à imaginação, concepção decorrente de uma época em que predominam o pensamento e a reflexão. Assim, Hegel, justifica a compreensão da arte como objeto do pensamento. A arte é em Hegel aquilo que, diante da complexidade ilusória (Täuschung) do mundo real, consegue erguer tais circunstâncias a uma realidade sublime (Erhaben), produto do espírito.

Hegel expõe a relação existente entre arte, filosofia e religião, no sentido de que esta primeira buscou sempre expressar o divino, as necessidades e exigências do espírito. Segundo ele, através da arte alguns povos manifestam suas mais nobres ideias e é artisticamente que por vezes, é possível compreender a religião de um povo. No entanto, a arte difere da religião e da filosofia no que concerne à manifestação artística advinda do espírito, como capaz de chegar a uma representação sensível por meio das ideias elevadas. 
A imitação não deve ser o conteúdo primordial da arte, tendo em vista que esta apenas é representação da realidade imediata e meio de satisfazer às lembranças. Ela está para além disso. Hegel não desconsidera de todo esta possibilidade, no entanto, considera que a busca do sentido artístico é na verdade pela manifestação da totalidade da vida e não apenas satisfação de representações imediatas.

Hegel defende na introdução da "Estética", a beleza artística como manifestação do espírito, explicita as possibilidades de uma filosofa da arte e considera a poesia o mais alto grau da espiritualidade, pois é manifestação da arte absoluta, enquanto expressão de autonomia e liberdade. Mas "os belos dias da arte grega, bem como a era de ouro da idade média tardia ficaram para trás": (Die schöne Tage der griechischen Kunst wie die goldene Zeit des späteren Mittelalsters sind vorüber). ${ }^{3}$ Além disso, para Hegel, após os tempos áureos na Grécia antiga, a arte não corresponde mais aos interesses supremos do espírito, pois ela se autonomiza em relação ao culto, à religiosidade.

[...] Hegel já teria percebido que quanto mais a obra de arte aprimora as possibilidades de sua visibilidade e exposição - o que em W. Benjamin é promovido pelos meios técnicos da reprodução artística -, tanto mais ela deixa de resguardar o caráter de culto, a religiosidade a qual servia, emancipando-se enquanto configuração sensível. ${ }^{4}$

A concepção hegeliana trata a arte como produto do espírito e não da complexidade do mundo real dominado pelos atributos racionais. Neste sentido, tomamos para dialogar com tal visão a proposta benjaminiana concernente à falta de autenticidade da obra de arte na era da reprodutibilidade técnica. Uma reflexão que desenvolveremos analisando o conceito de arte nestes dois autores, que reconhecemos trazerem diferenças históricas e conceituais diante do fenômeno artístico.

\section{ARTE EM BENJAMIN}

No início do texto "A obra de arte na era da reprodutibilidade técnica", Benjamin verifica que ocorreu uma distorção na verdadeira obra de arte, em um

\footnotetext{
3 HEGEL, Ästhetik, Seite 24.

${ }^{4}$ WERLE, 2004, p. 33.
} 
contexto de predomínio da técnica, quando a própria arte é vítima de uma reprodução desenfreada. Esta ascensão tecnicista foi possível a partir do advento das ciências e a confiança exacerbada na razão. Como ele mesmo expõs, a imitação sempre foi presença constante nas produções humanas, ou seja, o que um homem fazia, sempre podia ser imitado por outros, sendo que, em algumas vezes essa reprodução ocorria apenas para obtenção de lucro.

A reprodutibilidade técnica através de um processo de evolução histórica passa a atingir um grau de qualidade mais apurado na tentativa de reproduzir fielmente a realidade, buscando captar a totalidade e conquistar um espaço nos procedimentos artísticos. Para Benjamin, mesmo a reprodutibilidade técnica atingindo este objetivo de perfeição, faz com que a arte perca a autenticidade, sua quintessência na tradição, sua aura.

Ainda que a reprodução técnica consiga atingir certa autonomia com relação à reprodução manual, por atingir aspectos do original com maior fidelidade e assim aproximar o indivíduo da obra de arte, não é capaz de apreender o aqui e o agora da obra de arte. O aqui e o agora se refere à existência única da obra de arte e constitui a sua autenticidade ligada ao lugar no qual a obra se encontra. Por exemplo, uma estátua construída no século XVIII, poderá com o tempo perder certas características, mas permanecerá sempre idêntica a si mesma, pois está inserida em uma determinada tradição que possibilita identificá-la mesmo nos dias atuais, como sendo sempre aquele objeto com sua autenticidade.

Porém, a reprodutibilidade técnica faz com que a existência única da obra de arte converta-se em uma existência em série, neutralizando a aura compreendida como o encantamento ou a magia imanente à obra de arte autêntica. A magia da obra de arte é composta por elementos característicos do tempo e do espaço, remetendo-se à tradição predominante em seu contexto.

A produção em massa, visando cada vez mais à aproximação do homem com a obra de arte, através da reprodução constante é causadora do declínio da aura. Benjamin enfatiza a diferença entre a reprodução nas revistas e no cinema com relação à imagem. Na imagem é possível perceber unidade e durabilidade, enquanto que na reprodução nota-se transitoriedade e repetibilidade. 
A percepção humana é dotada de uma capacidade de transformar-se, ela não é única, pois os valores estéticos mudam. Partindo desse pressuposto, podemos verificar que a obra de arte é única e identifica-se com o contexto no qual está inserida. Segundo Benjamin, a mais antiga forma dessa inserção ocorre através do culto, sendo que as obras de arte surgem com a intenção de servirem aos rituais, sejam eles mágicos ou posteriormente religiosos, trazendo em seu cerne uma fundamentação teológica.

Há uma mudança, contudo, a partir da reprodução técnica. Por exemplo, a reprodução técnica da fotografia faz com que o vínculo da obra de arte com o ritual seja superado, passando a fundamentar-se em uma práxis: a política. Dessa forma, a arte perde sua autonomia, pois através da multiplicidade das cópias, a autenticidade artística passa a perder seu sentido e sua função social se transforma.

A exposição por meio da reprodução técnica também pode ser percebida na política, ou seja, a reprodução traz a dimensão política. Os discursos políticos antes proferidos apenas para o parlamento, passam, com a técnica, ao acesso ilimitado, abrangendo e atingindo um número maior de pessoas, dando possibilidade de manutenção do poder vigente. Ocorre então uma propagação ideológica, através do discurso, em que interesses particulares são tidos como universais.

Benjamin faz uma associação do surgimento das obras cinematográficas com o fascismo, ambos surgem a partir de uma crise e destacam interesses nacionais. $O$ fascismo busca, por meio da violência, estabelecer relações, enquanto que o cinema tenta atingir as massas através do valor de exposição. No entanto, observamos que Benjamin compreende o cinema a partir de um viés não apenas negativo, mas também e principalmente positivo. Assim, considera o cinema um instrumento de emancipação humana, ou seja, por mais que o cinema influencie negativamente, ele poderá ser visto positivamente por meio de seu papel emancipatório.

Se tomado negativamente, o cinema pode ser analisado pelo seu "caráter destruidor" presente na explosão reprodutora de imagens. A reprodução em massa corresponde à reprodução de concepções, desta forma, surge uma estetização da vida política, que por tentar abranger as massas acaba enaltecendo as guerras. Através das guerras a reprodutibilidade técnica atinge 0 auge de seu desenvolvimento, mas ao mesmo tempo mostra a fragilidade do homem na ilusão de 
acreditar que a técnica poderia estar suficientemente avançada "para controlar as forças elementares da sociedade" ${ }^{5}$, o que é um equívoco.

Neste sentido, a arte da exposição cinematográfica serve de aparelho de manipulação do homem, fazendo com que este homem se adeque as exigências do sistema tecnicista. Essa ação implícita tanto na fotografia quanto no filme expressa o caráter político existente na reprodutibilidade técnica como indicador de caminho. Segundo Benjamin,

Uma das funções sociais do cinema é criar um equilíbrio entre o homem e o aparelho. O cinema não realiza essa tarefa apenas pelo modo com que o homem se representa diante do aparelho, mas pelo modo com que representa o mundo, graças a esse aparelho. ${ }^{6}$

Em oposição à obra de arte grega que prezava por valores eternos, a obra de arte na era da reprodutibilidade técnica preza pela multiplicação das cópias em grande escala. Benjamin defende que o cinema está envolto por uma especulação capitalista que estimula o deslumbramento e consequentemente a atribuição de mera mercadoria. Assim, tomado por este sentido capitalista proporciona "a consciência corrupta das massas"”.

No entanto, ao considerarmos como o fez Benjamin, a função social do cinema, percebermos que quando a arte perde sua aura, ela se expõe, e esta exposição própria da arte cinematográfica faz com ocorra um desenvolvimento da habilidade da percepção. Assim, a arte perde sua função parasitária, pois não havia função social, mas prestava-se apenas como objeto de culto e, ao mesmo tempo, adquire na era da reprodutibilidade técnica, uma função de exposição. Nessa dinâmica, o cinema, ao estimular a percepção, faz com que a arte sobreviva diante das intempéries. No cenário da fantasmagoria moderna, encontramos no cinema a possibilidade de um equilíbrio, ou mais ainda, uma saída para as "psicoses de massa". É esse o lado "redentor", digamos assim, da técnica.

Sobressai-se então a questão: será que a reprodução tecnológica alterou a natureza da arte? Vários foram os teóricos que tentaram dar conta desta questão, ainda que superficialmente. Benjamin mostra como a arte foi perdendo sua

\footnotetext{
BENJAMIN, 1994, p. 196.

BENJAMIN, 1994, p. 189.

7 BENJAMIN, 1994, p. 180.
} 
autenticidade a partir da reprodutibilidade técnica. Pois o idêntico a si mesmo da obra de arte autêntica foi transformado em produção em massa, que apesar de permitir a acessibilidade artística a um maior número de pessoas acabou por favorecer os interesses particulares do capital e desfavorecer as características autênticas da obra de arte. No entanto, Benjamin modifica essa percepção, na medida em que encontra no cinema a possibilidade de uma "explosão terapêutica do inconsciente", só possibilitada pela sucessão de cenas, de que a técnica cinematográfica é capaz. Enquanto que na reflexão sobre a estética, em Hegel, o Belo surge como sendo próprio do espírito humano, percebemos que a arte perde seu caráter genuíno - sua aura - no momento em que o homem, sob o domínio da técnica moderna, desconfigura o sentido da arte, projetando nela outras funções. Neste sentido, Benjamin ao invés de lamentar o fim da arte como fez Hegel, recoloca suas ideias de diferentes maneiras por meio de outras expressões da arte, tal como o cinema.

Apesar do enfoque diferenciado entre os filósofos Wilhelm Friedrich Hegel e Walter Benjamin, consideramo-los fundamentais para analisarmos a crise da arte na modernidade. Posto que, em Hegel vimos uma transformação da arte a partir de um viés histórico enquanto que Benjamin destaca as mudanças do conceito de arte promovidas pelos meios técnicos. A situação da arte para Hegel deve ser compreendida no desenvolvimento do espírito como um todo e não a partir de elementos tidos como exteriores como na visão de Benjamin, algo que surge empiricamente no desenrolar da história.

\section{REFERÊNCIAS}

BENJAMIN, Walter. "A obra de arte na era da reprodutibilidade técnica". In: Magia e técnica, arte e política, Tradução de Sérgio Paulo Rouanet. $7^{a}$ Ed. São Paulo: Brasiliense, 1994.

CALLADO, Tereza de Castro. Walter Benjamin - A Experiência da Origem, Fortaleza: Eduece, 2006.

HEGEL, G. W. Friedrich. Estética. Tradução de Álvaro Ribeiro e Orlando Vitorino. Lisboa: Guimarães Editores, 1993.

WERLE, Marco Aurélio. Hegel e W. Benjamin: variações em torno da crise da arte na época moderna. KRITERION, Belo Horizonte, $n^{\circ} 109$, Jun/2004, p. 32-45. 
Michele Gomes Alves - Mestranda em Filosofia pela Universidade Estadual do Ceará-UECE, Brasileira, residente em Fortaleza - CE, E-mail: michelese@ hotmail.com 